\title{
Liver transcriptomic and proteomic profiles of preweaning lambs are modified by milk replacer restriction
}

\author{
A. Santos, F. J. Giráldez, J. Frutos, and S. Andrés* \\ Instituto de Ganadería de Montaña, CSIC-Universidad de León, Finca Marzanas, E-24346 Grulleros, León, Spain
}

\begin{abstract}
Prenatal and early postnatal nutrition may promote long-term effects on both feed efficiency and health of animals. Therefore, moderated milk replacer restriction during the artificial rearing period might negatively affect feed efficiency during the postweaning phases in dairy ewes. The aim of this work was to identify differentially expressed (DE) genes by RNA sequencing and differentially accumulated proteins using MALDI-TOF mass spectrometry in the liver of artificially reared Assaf lambs to identify modified metabolic pathways as a consequence of milk replacer restriction in order to find possible solutions to correct any detrimental effect caused by this factor. Forty female Assaf lambs were used in this experiment. The animals were penned individually and assigned randomly to 1 of 2 treatments groups $(\mathrm{n}=20$ per treatment). The first group of lambs was fed ad libitum (AL), whereas the second (restricted, RES) only received approximately $62.5 \%$ of the level of intake measured in the AL group. Eight 35-d-old lambs from each group (16 lambs in total) were harvested and a piece of liver of 8 lambs (4 AL and 4 RES lambs) was excised for transcriptomic and proteomic analysis. Differential gene expression analysis identified 386 $\mathrm{DE}$ genes [198 of them being annotated genes in the Kyoto Encyclopedia of Genes and Genomes (KEGG) pathway], with 176 downregulated and 210 upregulated in the early feed-restricted group relative to the $\mathrm{AL}$ group. A total of 26 spots were also differentially accumulated proteins in the liver of the 2 groups of lambs, 10 of them being down-accumulated whereas the other 16 evolved in the opposite way in the liver of RES relative to AL lambs. Collectively, both the transcriptomic and proteomic approaches revealed an upregulation of genes participating in oxidation of fatty acids in the early feed-restricted lambs. The expression of many genes involved in the degradation of several AA (e.g. alanine, valine, isoleucine, tyrosine) was also modified
\end{abstract}

Received May 24, 2018.

Accepted October 15, 2018

*Corresponding author: sonia.andres@eae.csic.es in the RES lambs, probably to render substrates for gluconeogenesis. Moreover, other genes involved in apoptosis, inflammation, or hepatic oxidative pathways were upregulated in these lambs. Finally, the expression of genes implicated in oxidative phosphorylation was modified in RES animals. Altogether all these modifications suggest that the partitioning and utilization of nutrients in the early feed-restricted lambs might have been modified, being partially responsible for changes during the replacement phase later in life.

Key words: feed efficiency, feed restriction, developmental origins of health and disease, metabolic programming

\section{INTRODUCTION}

Early feed restriction (pre- and perinatal life) modifies gene expression in several organs and tissues of the offspring, affecting not only the digestive and metabolic utilization of nutrients in different biological functions (Lillycrop et al., 2007; Altmann et al., 2012; Lan et al., 2013; Geraghty et al., 2016; Khanal and Nielsen, 2017) but also promoting metabolic disorders later in life due to nutritional programming events, as described previously in humans (González-Barranco and Ríos-Torres, 2004; Roseboom et al., 2011; Ruchat et al., 2014) and rats (Kang et al., 2011; Ellis et al., 2014). Regarding lambs, several studies have shown that metabolic programming events are caused by early feed restriction (Davies and Owen, 1967; Greenwood et al., 2004; Galvani et al., 2014), with negative long-term effects after the period of feed restriction. In this sense, previous studies have demonstrated negative consequences not only on the health status (Frutos et al., 2018) and feed efficiency traits (Santos et al., 2018c,d), but also on the onset of puberty in replacement ewes lambs (Santos et al., 2018c). However, even though we have found several studies in children (Ruchat et al., 2014), cattle (Soberon et al., 2012; Soberon and Van Amburgh, 2013; Alexandre et al., 2015), and pigs (Vincent et al., 2015), to our knowledge no studies have described the effects of early feed restriction at the gene expression level in artificially reared female Assaf lambs. There- 
fore, progress in this field may help us understand the mechanisms underlying nutritional programming and the adverse effects promoted by early undernutrition in replacement ewe lambs. Implementing early corrective strategies is crucial, as early feed restriction (which may happen in the farm as a consequence of environmental, health, or management conditions) might negatively affect future profitability of a dairy sheep farm. The present study aimed to identify both differentially expressed (DE) genes and differentially accumulated proteins (proteomics) in the liver of early feed-restricted lambs in order to understand both the mechanisms responsible for the alterations in the partitioning and utilization of nutrients of early feed-restricted lambs and those causing detrimental effects on reproductive and feed efficiency later in life in dairy sheep farms.

\section{MATERIAL AND METHODS}

\section{Care and Use of Animals}

All the recommendations of the Directive 2010/63/ EU of the European Parliament and of the Council on the protection of animals used for scientific purposes and the IGM-CSIC Animal Experimentation Committee (protocol number 2015-04) were carefully followed in all the handling practices involving animals.

\section{Animal Diets and Sampling}

Forty female Assaf lambs, individually penned during the artificial rearing period, were used in this experiment. The lambs were stratified based on live BW at birth (average $=4.73 \pm 0.116 \mathrm{~kg}$ ) and randomly allocated to 1 of 2 experimental treatments $(\mathrm{n}=20$ per dietary treatment) during the artificial rearing period. All the lambs were fed milk replacer (MR) 3 times daily $(0830,1400$, and $2030 \mathrm{~h}$ ) during the first week, and only twice daily (0830 and $1930 \mathrm{~h}$ ) during the rest of the suckling period. However, whereas the first group of lambs was fed MR ad libitum (AL; expected intake of 1.5 MJ of gross energy $/ \mathrm{kg}$ of metabolic BW, approximately 2.5 times maintenance energy requirements to gain a maximum of $250 \mathrm{~g} / \mathrm{d}$ ), the second group (restricted; RES) only received approximately $62.5 \%$ of MR intake as the AL group (approximately 1.5 times maintenance energy requirements to gain 100-120 g/d; NRC, 1985; Giráldez et al., 1999). The level of restriction was set according to previous studies carried out with milk-fed Assaf lambs (Manso et al., 1998; Castañares, 2008; Rodríguez et al., 2008). Ingredients and chemical composition of the MR administered are summarized in Table 1.
All the lambs were weighed twice a week throughout the artificial rearing period until they were $35 \mathrm{~d}$ old, when 8 representative animals from each group (16 lambs in total) were euthanized. Several pieces of liver were excised immediately, stabilized with RNAlater (Ambion Inc., Austin, TX) overnight at $4^{\circ} \mathrm{C}$, and then stored at $-80^{\circ} \mathrm{C}$ in order to study the liver transcriptomic and proteomic profiles. For this purpose, 4 liver samples from each group (8 lambs in total) were selected to cover the complete range of values of live BW at slaughter in each group and to avoid differences in birth weight between groups. Accumulated MR intake and animal performance of these preweaning lambs selected for omics ( 8 preweaning lambs in total) are summarized in Table 2 and Figure 1, whereas the rest of parameters measured at slaughter (16 preweaning lambs in total) are described in Santos et al. (2018c). The nonslaughtered animals (24 lambs in total) were weaned and fed ad libitum a TMR to study the effects of metabolic programming provoked by early feed restriction during the replacement phase (Frutos et al., 2018; Santos et al., 2018c). In the present study, only those data regarding liver transcriptomic and proteomic profiles of preweaning lamb (those slaughtered) are presented.

\section{Transcriptomics Analysis of Liver Samples Using RNA Sequencing}

A comparative liver transcriptome analysis was carried out using next-generation sequencing (RNA sequencing) as described in Santos et al. (2018c). Briefly, RNA extraction was performed in 4 liver samples per

Table 1. Ingredients and chemical composition ( $\mathrm{g} / \mathrm{kg}$ of DM, unless otherwise stated) of the commercial lamb milk replacer

\begin{tabular}{|c|c|}
\hline Item & Value \\
\hline \multicolumn{2}{|l|}{ Ingredient } \\
\hline Skim milk powder & 500 \\
\hline Milk whey powder & 160 \\
\hline Vegetable oil (cocoa) & 140 \\
\hline Animal fat (pork land) & 120 \\
\hline Whey protein powder & 40 \\
\hline Hydrolyzed wheat protein & 15 \\
\hline Yeast/sodium bicarbonate/dextrose & 15 \\
\hline PreVIT mineral $^{1}$ & 10 \\
\hline \multicolumn{2}{|l|}{ Chemical composition } \\
\hline $\mathrm{DM}, \mathrm{g} / \mathrm{kg}$ & 960 \\
\hline $\mathrm{CP}$ & 235 \\
\hline Ether extract & 260 \\
\hline Ash & 70 \\
\hline Metabolizable energy, $\mathrm{kcal} / \mathrm{kg}$ of $\mathrm{DM}$ & 5,089 \\
\hline
\end{tabular}

${ }^{1}$ Provided per $\mathrm{kg}$ of milk replacer: vitamin A, 80,000 IU; vitamin $\mathrm{D}_{3}$, 4,250 IU; iron, $40 \mathrm{mg}$; cobalt, $0.2 \mathrm{mg}$; copper, $5 \mathrm{mg}$; manganese, $25 \mathrm{mg}$; zinc, $30 \mathrm{mg}$; selenium, $0.2 \mathrm{mg}$ [Leches Maternizadas S.A. (LEMASA), León, Spain]. 


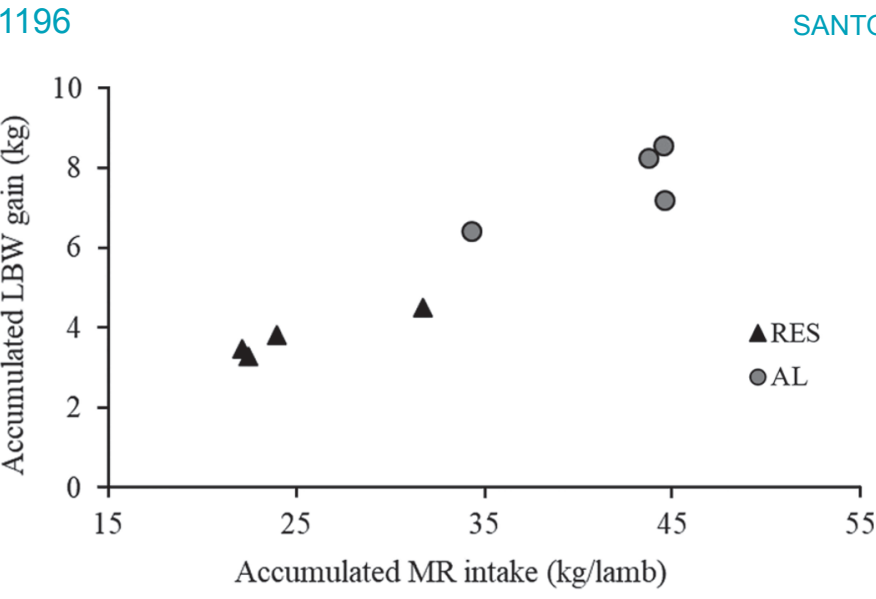

Figure 1. Accumulated live body weight (LBW) gain (kg) during the suckling period of lambs that were fed milk replacer (MR) ad libitum (AL) or restricted (RES).

group ( 8 samples in total), all of them presenting values for RNA integrity number larger than $8(8.5 \pm 0.04)$. The RNA sequencing (transcriptome sequencing) was thn carried out on an Illumina HiSeq 2500 sequencer (Illumina, San Diego, CA). The sequence and annotation of the most recent ovine genome assembly was obtained from the National Center for Biotechnology Information (NCBI) database (https://www.ncbi.nlm .nih.gov/; accession number GCF_000298735.2, assembly Oar_v4.0).

A differential expression analysis was completed with the Bioconductor package DESeq2 (version 1.12.4; Love et al., 2014), whereas statistical analyses of differentially expressed genes were carried out using $\mathrm{R}$ (version 3.3.1; R Core Team, 2016). The data were deposited in the Gene Expression Omnibus database (GEO; accession number GSE110192; https://www.ncbi.nlm.nih .gov/geo/). Genes were considered to be differentially expressed if their $P$-value, adjusted for multiple testing using the Benjamini and Hochberg method (false discovery rate), was less than 0.05 (Benjamini and Hochberg, 1995). The DE gene list was interpreted through enrichment analysis [Database for Annotation, Visualization and Integrated Discovery (DAVID, version 6.8; https://david.ncifcrf.gov/) and kegga function (Kyoto Encyclopedia of Genes and Genomes, KEGG) of the edgeR package (Robinson et al., 2010)].

\section{Proteomic Analysis of Liver Samples}

The procedure applied to study the liver proteome has been published previously in Santos et al. (2018d). Briefly, liver samples (4 animals per group, 8 samples in total) were homogenized, quantified for protein concentration with the Bradford assay (Bio-Rad Protein Assay, BioRad Laboratories, Hercules, CA), and stored at $-80^{\circ} \mathrm{C}$ or applied directly to $18-\mathrm{cm}$ immobilized $\mathrm{pH}$ gradient (IPG) strips (nonlinear gradient) before proteome resolution. Proteins were resolved in the first and second dimensions and then high-sensitivity colloidal Coomassie Blue G-250 Staining (blue silver, Sigma-Aldrich, Steinheim, Germany) of all the twodimensional gel electrophoresis was used for protein visualization ( 2 gels per sample, 8 gels per condition). Relative volume was calculated according to the volume of each spot divided by the total volume of all the spots in the gel. Differentially expressed proteins were considered when the ratio of the relative volume average between conditions was higher than 1.5 (fold change) and the $P$-value determined by Student's $t$-test was $<0.05$. These proteins were selected for identification (4800 MALDI TOF/TOF Analyzer, Applied Biosystems, Foster City, CA). Names of the proteins differentially accumulated in the liver were assigned according to GCF_000298735.2_Oar_v4.0. Identification of a certain protein was considered correct if the score was higher than 93 (protein score $>93 ; P<0.05$ ).

Table 2. Effect of milk replacer restriction on animal performance of preweaning lambs [4 ad libitum (AL) vs. 4 restricted (RES) lambs]

\begin{tabular}{|c|c|c|c|c|}
\hline Item & $\mathrm{AL}$ & RES & $\mathrm{RSD}^{1}$ & $P$-value \\
\hline Birth weight, kg & 3.99 & 4.12 & 0.192 & 0.409 \\
\hline Suckling period, ${ }^{2} \mathrm{~d}$ & 35.0 & 34.3 & 1.50 & 0.494 \\
\hline Accumulated milk replacer intake, $\mathrm{kg}$ & 41.8 & 25.1 & 4.77 & 0.002 \\
\hline $\mathrm{ADG},{ }^{3} \mathrm{~g} / \mathrm{d}$ & 199 & 99.8 & 14.59 & $<0.001$ \\
\hline Slaughter weight, kg & 11.6 & 7.90 & 0.739 & $<0.001$ \\
\hline Hot carcass weight, $\mathrm{kg}$ & 5.65 & 3.57 & 0.407 & $<0.001$ \\
\hline Cold carcass weight, $\mathrm{kg}$ & 5.44 & 3.40 & 0.396 & $<0.001$ \\
\hline Omental fat, $g$ & 101 & 19.4 & 11.57 & $<0.001$ \\
\hline Mesenteric fat, g & 102 & 53.3 & 14.11 & 0.003 \\
\hline Perirenal fat, $g$ & 104 & 34.6 & 19.99 & 0.002 \\
\hline
\end{tabular}

${ }^{1}$ Residual standard deviation.

${ }^{2}$ Artificial rearing phase, from birth to slaughter.

${ }^{3} \mathrm{ADG}$ during the suckling period. 


\section{RESULTS AND DISCUSSION}

Several studies have demonstrated that postnatal feed restriction of lambs may induce early nutritional programming, thus affecting the metabolism, growth, development, feed efficiency, and health throughout life (Davies and Owen, 1967; Greenwood et al., 2004; Galvani et al., 2014; Santos et al., 2018a,b,c,d). However, in-depth understanding of the early physiological processes promoted by this postnatal feed restriction on preweaning lambs is lacking. We present a complete differential transcriptome and proteome analysis of liver samples corresponding to artificially reared Assaf lambs fed MR ad libitum or restricted during this phase of life.

Differential gene expression analysis in the hepatic tissue of suckling Assaf lambs identified 386 DE genes, 198 of them being annotated genes in the KEGG pathway. Positive values of $\log _{2}$-fold change showed that 210 genes were upregulated in the RES relative to the AL group, whereas negative $\log _{2}$-fold change values denoted the downregulation of 176 genes (Supplemental Table S1; https://doi.org/10.3168/jds.2018-15110). The DAVID software and KEGG functional enrichment analysis identified functional gene clusters and pathways modified by milk replacer restriction, mainly related to the cytochrome P450, steroid hormone biosynthesis, AA metabolism, glycolysis/gluconeogenesis, and drug and xenobiotic metabolism. The most important terms and pathways are summarized in Tables 3 and 4 .

The proteomic profile of the liver identified 26 differentially accumulated $(P<0.05)$ spots/proteins (Figure 2 and Table 5), 10 of them being down-accumulated whereas the other 16 evolved in the opposite way in the liver of RES lambs.

\section{Carbohydrate Metabolic Pathways}

After birth, animals have to be adapted to a new situation and emerging new metabolic pathways (Baldwin et al., 2004; Davis and Fiorotto, 2005; van den Borne et al., 2007). In this context, nutrient supply could modulate these adaptive changes, meaning suboptimal nutrition in the early life could promote long-term effects on health and feed efficiency with important economic implications during the postweaning phases (Santos et al., 2018a,b,c,d). For example, during the suckling period, gluconeogenesis is increased to maintain normoglycemia (Ferré et al., 1986; Girard, 1990) to the point that this metabolic route provides $\sim 75 \%$ of the total glucose needs of neonatal ruminants (Nafikov and Beitz, 2007). However, in the present study, RES lambs were feed restricted, so a higher gluconeogenesis rate was expected in these animals to cover the glucose requirements of the tissues. Accordingly, in the present study, the expression of some genes related to the glycolysis and gluconeogenesis (e.g., GAPDH, PFKL, $G P I$, and $A D H 1 C$ ) were upregulated, whereas that encoding glycogen synthase (e.g., GYS2, which is one of the main enzymes involved in the synthesis of glycogen) was downregulated in the RES lambs. These functional changes were corroborated by the proteomic profile of artificially reared lambs, where several proteins involved in glycolytic/gluconeogenic pathways (e.g., fructose-bisphosphate aldolase B and glyceraldehyde3-phosphate DH) were differentially expressed in RES lambs (Table 5).

Likewise, it is interesting to note that PDHA1 [pyruvate dehydrogenase (lipoamide) alpha 1], which catalyzes the irreversible conversion of pyruvate into acetyl-CoA (Fu et al., 2017), was down-expressed in the RES lambs. This fact might have directed at least part of the intermediates of glycolysis toward biosynthetic pathways (e.g., pentose phosphate pathway) instead of tricarboxylic acid cycle (TAC; Salway, 2004). Accordingly, the expression of genes involved in TAC (e.g., $I D H 2$ and $O G D H$ ), oxidative phosphorylation (e.g., ATP6VOE2 and LOC101119721), and energy metabolism (e.g., CKMT2) was affected in RES lambs, whereas the upregulation of cytoplasmic aconitate hydratase (an enzyme involved in TAC) might be explained by its moonlighting functions, as it is involved in iron homeostasis when cellular iron levels are low (such as occurs under feed restriction). All these changes are in accordance with the results obtained by Akbar et al. (2013) in feed-restricted dairy cows, who observed an increased expression of genes associated with gluconeogenesis and the inhibition of mitochondrial oxidative phosphorylation during mid-lactation.

Conversely, as mentioned previously, the pentose phosphate pathway seemed to be activated in the RES lambs (e.g., upregulation of PRPS2), thus producing NADPH to be used in the biosynthetic pathways prevalent in the growing lambs (Wood, 1985). Together with the increased expression of genes related to nucleotides (e.g., XDH, LOC101109035, NT5E, AKr , LOC101106419, CMAS, and PRPS2), components of the cell membranes such as glycerophospholipids (e.g., PEMT; Gimenez et al., 2011), nucleoporins involved in RNA transport (e.g., NUP210, NUP62, and NDC1), ribosome biogenesis (e.g., POP7 LOC101102787, LOC101104725, and RPL22L1), and the production of vitamins and cofactors (e.g., TKFC, PNPO, NNT, BTD, SPR, LOC101103439, LOC101104703, DHRS3, $L O C 101119050$, and BCO1), these modifications seem to be indicative of an attempt of the growing organism for maintaining natural physiological functions for 
Table 3. Annotation clusters identified by the functional annotation tool of DAVID (https://david.ncifcrf .gov/) from the list of 386 differentially expressed genes [DESeq2; Love et al., $2014\left(P\right.$. BH $\left.<0.05^{1}\right)$ ] in the livers of preweaning lambs fed milk replacer ad libitum (AL) or restricted (RES)

\begin{tabular}{|c|c|c|}
\hline Term & No. ${ }^{2}$ & $P$-value \\
\hline \multicolumn{3}{|l|}{ Annotation cluster 1 (enrichment score: 11.666$)$} \\
\hline Steroid hormone biosynthesis & 22 & $9.62 \mathrm{E}-18$ \\
\hline Retinol metabolism & 21 & $3.52 \mathrm{E}-17$ \\
\hline Drug metabolism - cytochrome P450 & 19 & $1.86 \mathrm{E}-15$ \\
\hline Metabolism of xenobiotics by cytochrome P450 & 19 & $1.61 \mathrm{E}-14$ \\
\hline Ascorbate and aldarate metabolism & 12 & $2.84 \mathrm{E}-12$ \\
\hline UDP-glucuronosyl/UDP-glucosyltransferase & 10 & $4.36 \mathrm{E}-12$ \\
\hline Pentose and glucuronate interconversions & 13 & $7.88 \mathrm{E}-12$ \\
\hline Glucuronosyltransferase activity & 10 & $4.99 \mathrm{E}-11$ \\
\hline Drug metabolism - other enzymes & 13 & $1.48 \mathrm{E}-10$ \\
\hline Porphyrin and chlorophyll metabolism & 13 & $1.48 \mathrm{E}-10$ \\
\hline Metabolic process & 14 & $1.76 \mathrm{E}-07$ \\
\hline Glycosyltransferase & 13 & $6.55 \mathrm{E}-07$ \\
\hline \multicolumn{3}{|l|}{ Annotation cluster 2 (enrichment score: 6.521 ) } \\
\hline Biosynthesis of amino acids & 12 & $1.62 \mathrm{E}-06$ \\
\hline Carbon metabolism & 14 & $4.82 \mathrm{E}-06$ \\
\hline \multicolumn{3}{|l|}{ Annotation cluster 3 (enrichment score: 3.605 ) } \\
\hline NADP-dependent oxidoreductase domain & 7 & $1.28 \mathrm{E}-06$ \\
\hline Aldo/keto reductase subgroup & 6 & $5.18 \mathrm{E}-06$ \\
\hline Aldo/keto reductase & 6 & $2.08 \mathrm{E}-05$ \\
\hline Aldo/keto reductase, conserved site & 5 & $9.49 \mathrm{E}-05$ \\
\hline Aldo-keto reductase & 6 & $1.18 \mathrm{E}-04$ \\
\hline Oxidoreductase activity & 10 & $1.78 \mathrm{E}-04$ \\
\hline Ovarian steroidogenesis & 4 & $1.53 \mathrm{E}-01$ \\
\hline Arachidonic acid metabolism & 4 & $3.42 \mathrm{E}-01$ \\
\hline \multicolumn{3}{|l|}{ Annotation cluster 4 (enrichment score: 2.126 ) } \\
\hline Iron & 10 & 4.77E-04 \\
\hline Iron ion binding & 10 & $1.75 \mathrm{E}-03$ \\
\hline Heme binding & 9 & $2.58 \mathrm{E}-03$ \\
\hline Heme & 7 & $3.44 \mathrm{E}-03$ \\
\hline Cytochrome P450 & 5 & $1.61 \mathrm{E}-02$ \\
\hline Monooxygenase & 4 & $6.61 \mathrm{E}-02$ \\
\hline Cytochrome P450, conserved site & 3 & $1.67 \mathrm{E}-01$ \\
\hline \multicolumn{3}{|l|}{ Annotation cluster 5 (enrichment score: 1.918 ) } \\
\hline Pyridoxal phosphate-dependent transferase, major region, subdomain 2 & 5 & $6.63 \mathrm{E}-3$ \\
\hline Pyridoxal phosphate-dependent transferase, major region, subdomain 1 & 5 & $9.45 \mathrm{E}-3$ \\
\hline Pyridoxal phosphate-dependent transferase & 5 & $9.45 \mathrm{E}-3$ \\
\hline Pyridoxal phosphate binding & 5 & $1.92 \mathrm{E}-2$ \\
\hline Pyridoxal phosphate & 4 & $2.25 \mathrm{E}-2$ \\
\hline \multicolumn{3}{|l|}{ Annotation cluster 6 (enrichment score: 1.829$)$} \\
\hline CO dehydrogenase flavoprotein-like, FAD-binding, subdomain 2 & 3 & $1.02 \mathrm{E}-2$ \\
\hline Oxidoreductase activity, acting on $\mathrm{CH}-\mathrm{OH}$ group of donors & 3 & $1.28 \mathrm{E}-2$ \\
\hline FAD-binding, type 2 & 3 & $1.29 \mathrm{E}-2$ \\
\hline Flavin adenine dinucleotide binding & 5 & $2.88 \mathrm{E}-2$ \\
\hline \multicolumn{3}{|l|}{ Annotation cluster 7 (enrichment score: 1.679 ) } \\
\hline Carbohydrate kinase, FGGY, C-terminal & 3 & $5.60 \mathrm{E}-3$ \\
\hline Carbohydrate kinase, FGGY, N-terminal & 3 & $7.74 \mathrm{E}-3$ \\
\hline Keto-sugar kinase & 3 & $1.40 \mathrm{E}-2$ \\
\hline Carbohydrate metabolic process & 4 & $3.17 \mathrm{E}-1$ \\
\hline
\end{tabular}

${ }^{1} P . \mathrm{BH}<0.05=P$-value, adjusted for multiple testing using the Benjamini and Hochberg method (false discovery rate), was less than 0.05 (Benjamini and Hochberg, 1995).

${ }^{2}$ Number of genes involved in each term.

growth, such as cell proliferation, differentiation, and gene expression under feed restriction conditions.

\section{Protein Metabolic Pathways}

Keogh et al. (2016) demonstrated an increment of the expression of genes related to ribosomal functions (RPL22, RPL23, RPL26, RP6S, or POP1) that might point towards enhanced protein biosynthesis in restricted-fed animals. This seems to be in agreement with the overaccumulation of glycine amidinotransferase (an intermediate of creatine) in the liver proteome of RES lambs as an attempt to increase muscle development under feed restriction conditions.

However, under feed restriction, protein accretion might be reduced by both a lack of nutrients and an 
Table 4. Enriched Kyoto Encyclopedia of Genes and Genomes (KEGG) terms from the list of 386 differentially expressed genes [DESeq2 (Love et al., 2014; $P$. BH $<0.05^{1}$ )] in the livers of preweaning lambs fed milk replacer ad libitum (AL) or restricted (RES)

\begin{tabular}{|c|c|c|}
\hline Enriched KEGG pathways & $\mathrm{No}^{2}$ & $P$-value \\
\hline Metabolic pathways & 97 & $<0.001$ \\
\hline Steroid hormone biosynthesis & 24 & $<0.001$ \\
\hline Retinol metabolism & 22 & $<0.001$ \\
\hline Drug metabolism, cytochrome P450 & 19 & $<0.001$ \\
\hline Metabolism of xenobiotics by cytochrome P450 & 19 & $<0.001$ \\
\hline Ascorbate and aldarate metabolism & 12 & $<0.001$ \\
\hline Pentose and glucuronate interconversions & 13 & $<0.001$ \\
\hline Porphyrin and chlorophyll metabolism & 13 & $<0.001$ \\
\hline Drug metabolism, other enzymes & 13 & $<0.001$ \\
\hline Biosynthesis of AA & 12 & $<0.001$ \\
\hline Carbon metabolism & 14 & $<0.001$ \\
\hline Glutathione metabolism & 8 & $<0.001$ \\
\hline Glycine, serine and threonine metabolism & 7 & $<0.001$ \\
\hline Cysteine and methionine metabolism & 7 & $<0.001$ \\
\hline Arginine and proline metabolism & 7 & $<0.001$ \\
\hline Biosynthesis of UFA & 5 & $<0.001$ \\
\hline Fatty acid elongation & 5 & $<0.001$ \\
\hline Vitamin $B_{6}$ metabolism & 3 & $<0.001$ \\
\hline 2-Oxocarboxylic acid metabolism & 4 & $<0.001$ \\
\hline Fatty acid metabolism & 6 & 0.001 \\
\hline Arginine biosynthesis & 4 & 0.002 \\
\hline Alanine, aspartate, and glutamate metabolism & 5 & 0.003 \\
\hline Tyrosine metabolism & 5 & 0.003 \\
\hline Sulfur metabolism & 3 & 0.003 \\
\hline Valine, leucine, and isoleucine biosynthesis & 2 & 0.003 \\
\hline Peroxisome & 7 & 0.004 \\
\hline Glycolysis/gluconeogenesis & 6 & 0.005 \\
\hline Tryptophan metabolism & 5 & 0.007 \\
\hline Fructose and mannose metabolism & 4 & 0.008 \\
\hline Nitrogen metabolism & 3 & 0.009 \\
\hline PPAR signaling pathway & 6 & 0.009 \\
\hline Selenocompound metabolism & 3 & 0.013 \\
\hline Ovarian steroidogenesis & 5 & 0.017 \\
\hline Fatty acid degradation & 4 & 0.020 \\
\hline $\begin{array}{l}\text { Glycosaminoglycan biosynthesis, } \\
\text { heparan sulfate/heparin }\end{array}$ & 3 & 0.022 \\
\hline Phenylalanine metabolism & 3 & 0.024 \\
\hline Arachidonic acid metabolism & 6 & 0.027 \\
\hline Amino sugar and nucleotide sugar metabolism & 4 & 0.034 \\
\hline Nicotinate and nicotinamide metabolism & 3 & 0.035 \\
\hline Pentose phosphate pathway & 3 & 0.038 \\
\hline Valine, leucine and isoleucine degradation & 4 & 0.039 \\
\hline Starch and sucrose metabolism & 3 & 0.045 \\
\hline Citrate cycle (tricarboxylic acid cycle) & 3 & 0.052 \\
\hline Biotin metabolism & 1 & 0.071 \\
\hline Purine metabolism & 8 & 0.072 \\
\hline Lysine degradation & 4 & 0.078 \\
\hline Cell cycle & 6 & 0.094 \\
\hline
\end{tabular}

increased catabolism of some AA to produce gluconeogenic precursors (James, 1972; Goodman et al., 1980; Dhahbi et al., 2001; Velez and Donkin, 2005). Accordingly, in the present study, the expression of genes involved in the catabolism of several AA (e.g., Ala, Cys, Met, Val, Leu, Ile, Tyr, and so on) was upregulated in the RES lambs. Nevertheless, those involved in lysine degradation (e.g., PLOD2, AASS) were downregulated. Moreover, the down-expression of genes related to protein processing in endoplasmic reticulum (e.g., TXNDC12) might have increased terminally misfolded proteins directed toward degradation through the proteasome (Galligan and Petersen, 2012; Lee and Lee, 2017), which also presented genes modified by feed restriction (e.g., PSMB9 and PSMD6). Consequently, the accumulation of misfolded proteins in the endoplasmic reticulum might have increased protein catabolism, thus causing stress and, hence, the apoptosis of cells (e.g., PERP was upregulated in RES lambs), as further explained below. All these results at transcriptome level match those observed in the liver proteome profile, where peptidyl-prolyl cis-trans isomerase A-like isoform X2 (involved in both protein folding and targeting for proteasomal degradation) and protein-disulfide isomerase (involved in protein folding) were up- and downregulated, respectively, in the liver of RES lambs. Moreover, several enzymes involved in AA degradation (e.g., 3-hydroxyisobutyryl-CoA hydrolase, mitochondrial isoform $\mathrm{X} 1$, aminomethyltransferase, mitochondrial isoform X2) and protein catabolism (e.g., selenium-binding protein 1 isoform X1) were upregulated, whereas 2-iminobutanoate/2-iminopropanoate deaminase (involved in the isoleucine biosynthesis) was downregulated in the liver of RES lambs. It must be stressed that the expression of genes encoding enzymes involved in urea cycle (e.g., CPS1, OAT, and ARG1) was downregulated in the RES lambs, probably as a compensatory mechanism to favor nitrogen retention (James, 1972; Velez and Donkin, 2005). Therefore, the RES lambs might have increased the degradation of some AA to produce gluconeogenic precursors, but attempted to reduce time nitrogen losses at the same to maintain physiological normal growth under feed restriction conditions.

\section{Lipid Metabolic Pathways}

Feed restriction decreased the expression of genes related to the differentiation of adipocytes (e.g., PLIN2), synthesis of glycerolipids (e.g., MOGAT1), and longchain fatty acids (e.g., ELOVL4, ELOVL7). This is in agreement with the down-expression of thiosulfate sulfurtransferase in the liver proteome of RES lambs, which is expressed selectively in adipocytes (Morton et al., 2016). Moreover, the expression of genes involved in the oxidation of a variety of organic substrates (e.g., $S O R D, A D H 1 C$ ) and $\beta$-oxidation of fatty acids (e.g., ECI1 and ECHS1) was increased in RES lambs. All these modifications at the transcriptome level might be related to functional changes [3-ketoacyl-CoA thiolase, peroxisomal isoform X2 (involved in $\beta$-oxidation 


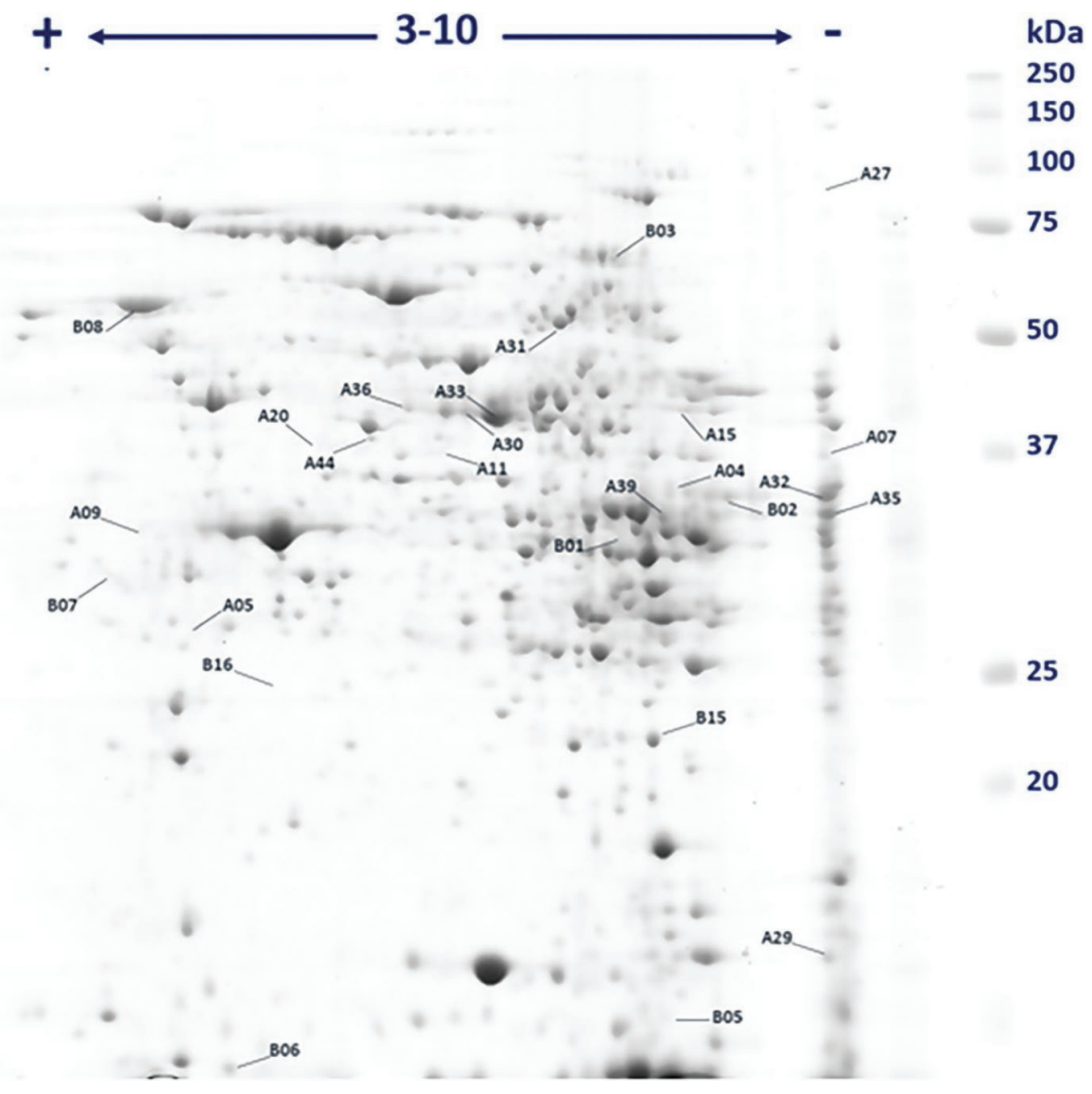

Figure 2. Representative colloidal Coomassie Blue (Sigma-Aldrich, Steinheim, Germany) stained 2-dimensional electrophoresis gel of a liver from early milk restricted lambs. A total of $450 \mu \mathrm{g}$ of protein was loaded, and 2-dimensional gel electrophoresis was performed using a pH range of 3 to 10 in the first dimension and SDS-PAGE (12.5-15\% total acrylamide) in the second dimension. Marked spot numbers refer to spot identification in Table 5. Twenty-four spots/proteins were identified using MALDI-TOF/TOF tandem mass spectrometry analysis.

at peroxisomal level) was upregulated in the liver of RES lambs], which likely occur to render acetyl-CoA and glycerol (gluconeogenic precursor) through lipolysis and $\beta$-oxidation. In fact, Girard (1986) suggested that active hepatic fatty acid oxidation is necessary in the newborn to support hepatic gluconeogenesis by providing essential cofactors, such as acetyl CoA and NADPH.

Moreover, the hepatic fatty acid oxidation (coming either from the diet or fat depots) is fundamental to sustain protein accretion in growing lambs under feed restriction (Giráldez et al., 1999). However, fat mobilized from adipose tissue to liver for acetyl CoA production during feed restriction may cause hepatic steatosis (Xu et al., 2012; Santos et al., 2018b) and a concomitant increased expression of glucuronosyltransferases
(Yu et al., 2004; Xu et al., 2012). All these observations are in accordance with the results observed in our RES lambs (e.g., upregulation of UGT1A6, UGT1A9, $U G T 2 A 1$, and $U G T 2 B 7$ ) and may have implications in the conjugation reaction (via glucuronide) in phase II metabolism of drugs and xenobiotics. In addition, apart from the upregulation of $U G T$ in the RES group, other genes related to the metabolism of drugs and xenobiotics were altered by early feed restriction. Thus, genes (e.g., LOC101105651, LOC101112384, and EPHX1) encoding phase I enzymes (i.e., oxidizing), belonging predominantly to the cytochrome P450 family (e.g., CYP2C19, CYP2D14), and others related to phase II (i.e., conjugation), such as glutathione transferases (e.g., GSTA1-1, and GSTT2B) and glycine N-acyltransferase (e.g., LOC101108419 and LOC101108685), were over- 
expressed in the RES lambs, which is in agreement with the results observed by Grubbs et al. (2013) in low-efficient pigs. However, protein synthesis could be repressed as a consequence of the lack of nutrients in the RES lambs (Yu et al., 2004; Xu et al., 2012), as previously stated.

\section{Oxidative Stress and Cellular Damage Metabolic Pathways}

Malnutrition provokes disorders in the peroxisomes, which are the organelles preventing the accumulation of steroid acids_(van Zutphen et al., 2016). Accordingly, our results in the early feed-restricted group indicate the upregulation of many genes involved in metabolic pathways (e.g., steroid and steroid hormone biosynthesis, primary bile acid biosynthesis, and bile secretion). All these modifications might increase plasma levels of several cholesterol metabolites, such as oxysterols, bile alcohols, or bile acids, contributing to hepatic toxicity and damage (van Zutphen et al., 2016; Zhang et al.,
2016), thus inducing the production of reactive oxygen/ nitrogen species and the initiation of apoptotic pathways (e.g., PERP is overexpressed in RES; Zhang et al., 2016). Therefore, in accordance with Grubbs et al. (2013), the increased expression of superoxide dismutase (e.g., SOD1 and LOC101115136) and glutathione-Stransferase in the RES lambs (e.g., MGST1, which is involved in the production of inflammation mediators, such as leukotrienes or prostaglandin E) may indicate liver injury. Accordingly, recent studies have revealed that peptidyl-prolyl cis-trans isomerase A (which was overaccumulated in the liver of RES lambs) can be secreted by cells in response to inflammatory stimuli and oxidative stress (Jin et al., 2000, 2004; Nigro et al., 2013). In fact, these results corroborate the proinflammatory profile observed by metabolomics in the weaned lambs of the present experiment (nonslaughtered animals) during the replacement phase (Santos et al., 2018c). However, the apparently contradictory downaccumulation of mitochondrial superoxide dismutase in the liver proteome of RES lambs might have been

Table 5. List of spots/proteins identified by MALDI-TOF/TOF tandem mass spectrometry analysis on the lamb liver 2-dimensional gel electrophoresis gel and differentially accumulated in the livers of preweaning lambs fed milk replacer ad libitum (AL) or restricted (RES)

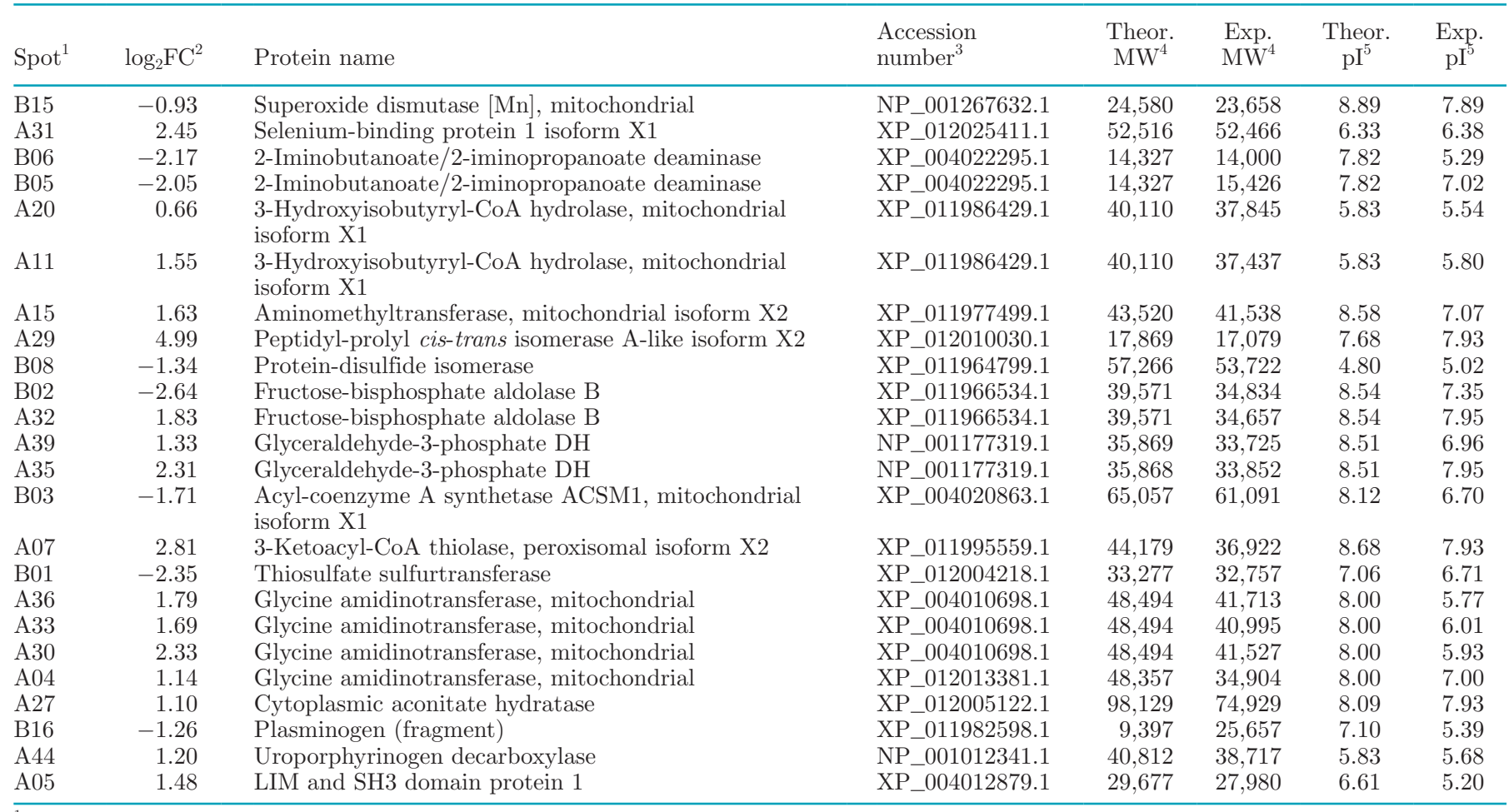

${ }^{1}$ Spots number labelled in Figure 2. Spots A09 and B07 were not included in Table 4 because they were not identified as Ovis aries proteins.

${ }^{2} \log _{2}$ fold change of the relative volume average (positive value if RES/ADL >0.58; negative value if AL/RES >0.58).

${ }^{3}$ Accession number from NCBI database (https://www.ncbi.nlm.nih.gov/).

${ }^{4} \mathrm{MW}=$ molecular weight (Dalton), theoretical (Theor.) and experimental (Exp.).

${ }^{5} \mathrm{pI}=$ isoelectric point, theoretical (Theor.) and experimental (Exp.). 
promoted by a reduced propagation of free radicals generated through oxidative phosphorylation because of the lower nutrient intake level (Sohal et al., 1994).

\section{Other Metabolic Functions}

Several other functions might have been affected by early feed restriction. It is noteworthy that $S T S$ was the only gene involved in the steroid hormone synthesis pathway that was down-expressed in the RES lambs. This gene has a crucial role in regulating the formation of biologically active sex steroids, such as estrogens (Reed et al., 2005); in fact, physiologically upregulated STS activity before puberty has been shown in humans (Idkowiak et al., 2016). In addition, it is interesting to note the downregulation of one of the genes (e.g., $S P R$ ) involved in the metabolic route related to folate biosynthesis; folate has been involved in epigenetic mechanisms (Crider et al., 2012), such as DNA methylation in the preovulatory oocyte or preimplantation embryo (Sinclair et al., 2007; Dupont et al., 2012). Consequently, the downregulation of both genes might be involved in the mechanisms that explain delays the onset of puberty after early feed restriction and impairment of reproductive functions in dairy ewes (Robinson et al., 2002, 2005). Accordingly, a delay in the onset of the first ovulation was observed in the replacement ewe lambs of the present study, as described previously in a different paper (Santos et al., 2018c).

Furthermore, Amadi et al. (2009) also described a reduced expression of heparan sulfate proteoglycan $(H S P G)$ in enterocytes of children with Kwashiorkor that finally provoked intestinal protein loss and edema; in our study, genes involved in glycosaminoglycan biosynthesis and heparan sulfate (e.g., GLCE and NDST3) were down-expressed in RES lambs. Notwithstanding, the existence of differences in a specific tissue (e.g., liver) does not entail the same effect at other locations (Tizioto et al., 2015).

\section{CONCLUSIONS}

According to the results obtained in the present study, early feed restriction during the artificial rearing period of Assaf lambs increases the oxidation of fatty acids and the hepatic oxidative stress, whereas protein synthesis and degradation were also modified to sustain gluconeogenic pathways. All these changes, together with the differential expression of genes involved in oxidative phosphorylation, may modify the partitioning and utilization of nutrients in early feed-restricted lambs.

\section{ACKNOWLEDGMENTS}

This work was supported by the Spanish Ministry of Economy, Industry and Competitiveness (MINECO, AGL2014-54124R). Alba Santos gratefully acknowledges receipt of a predoctoral grant from the Spanish Ministry of Education, Culture and Sport (MECD, FPU15/01630). The authors would like to thank David Kenny (TEAGASC, Animal \& Grassland Research and Innovation Centre, Grange, Dunsany, Ireland) for his assistance with the English revision. We would also like to thank Instituto de Biotecnología de León (INBIOTEC), León, Spain, for the technical support with -omics. The authors declare no conflicts of interest.

\section{REFERENCES}

Akbar, H., M. Bionaz, D. B. Carlson, S. L. Rodriguez-Zas, R. E. Everts, H. A. Lewin, J. K. Drackley, and J. J. Loor. 2013. Feed restriction, but not L-carnitine infusion, alters the liver transcriptome by inhibiting sterol synthesis and mitochondrial oxidative phosphorylation and increasing gluconeogenesis in mid-lactation dairy cows. J. Dairy Sci. 96:2201-2213. https://doi.org/10.3168/ jds.2012-6036.

Alexandre, P. A., L. J. A. Kogelman, M. H. A. Santana, D. Passarelli, L. H. Pulz, P. Fantinato-Neto, P. L. Silva, P. R. Leme, R. F. Strefezzi, L. L. Coutinho, J. B. S. Ferraz, J. P. Eler, H. N. Kadarmideen, and H. Fukumasu. 2015. Liver transcriptomic networks reveal main biological processes associated with feed efficiency in beef cattle. BMC Genomics 16:1073. https://doi.org/10 $.1186 / \mathrm{s} 12864-015-2292-8$.

Altmann, S., E. Murani, M. Schwerin, C. C. Metges, K. Wimmers, and S. Ponsuksili. 2012. Maternal dietary protein restriction and excess affects offspring gene expression and methylation of non-SMC subunits of condensin I in liver and skeletal muscle. Epigenetics 7:239-252. https://doi.org/10.4161/epi.7.3.19183.

Amadi, B., A. O. Fagbemi, P. Kelly, M. Mwiya, F. Torrente, C. Salvestrini, R. Day, M. H. Golden, E. A. Eklund, H. H. Freeze, and S. H. Murch. 2009. Reduced production of sulfated glycosaminoglycans occurs in Zambian children with kwashiorkor but not marasmus. Am. J. Clin. Nutr. 89:592-600. https://doi.org/10.3945/ajcn.2008 .27092 .

Baldwin, R. L., K. R. McLeod, J. L. Klotz, and R. N. Heitman. 2004. Rumen development, intestinal growth and hepatic metabolism in the pre- and postweaning ruminant. J. Dairy Sci. 87(E. Suppl.):E55E65. https://doi.org/10.3168/jds.S0022-0302(04)70061-2.

Benjamini, Y., and Y. Hochberg. 1995. Controlling the false discovery rate: A practical and powerful approach to multiple testing. J. R. Stat. Soc. Series B Stat. Methodol. 57:289-300. https://doi.org/ $10.2307 / 2346101$.

Castañares, N. 2008. Recría de corderas de raza Assaf española. Efecto de la alimentación entre el nacimiento y los cinco meses de edad sobre el crecimiento de los animales, el desarrollo de la glándula mamaria y la producción de leche en la primera lactación. $\mathrm{PhD}$ Diss. Departamento de Producción Animal, Universidad de León, León, Spain.

Crider, K. S., T. P. Yang, R. J. Berry, and L. B. Bailey. 2012. Folate and DNA methylation: A review of molecular mechanisms and the evidence for folate's role. Adv. Nutr. 3:21-38. https://doi.org/10 .3945 /an.111.000992.

Davies, D. A. R., and J. B. Owen. 1967. The intensive rearing of lambs 1. Some factors affecting performance in the liquid feeding period. Anim. Sci. 9:501-508. https://doi.org/10.1017/ S0003356100042070. 
Davis, T. A., and M. L. Fiorotto. 2005. Regulation of skeletal muscle protein metabolism in growing animals. Pages 35-68 in Biology of Metabolism in Growing Animals. Vol. 3. D. G. Burrin and H. J. Mersmann, ed. Elsevier, London, UK. https://doi.org/10.1016/ S1877-1823(09)70009-8.

Dhahbi, J. M., P. L. Mote, J. Wingo, B. C. Rowley, S. X. Cao, R. L. Walford, and S. R. Spindler. 2001. Caloric restriction alters the feeding response of key metabolic enzyme genes. Mech. Ageing Dev. 122:1033-1048. https://doi.org/10.1016/S0047-6374(01)00230-5.

Dupont, C., A. G. Cordier, C. Junien, B. Mandon-Pépin, R. Levy, and P. Chavatte-Palmer. 2012. Maternal environment and the reproductive function of the offspring. Theriogenology 78:1405-1414. https://doi.org/10.1016/j.theriogenology.2012.06.016.

Ellis, P. J., T. J. Morris, B. M. Skinner, C. A. Sargent, M. H. Vickers, P. D. Gluckman, S. Gilmour, and N. A. Affara. 2014. Thrifty metabolic programming in rats is induced by both maternal undernutrition and postnatal leptin treatment, but masked in the presence of both: Implications for models of developmental programming. BMC Genomics 15:49. https://doi.org/10.1186/1471-2164-15-49.

Ferré, P., J. F. Decaux, T. Issad, and J. Girard. 1986. Changes in energy metabolism during the suckling and weaning period in the newborn. Reprod. Nutr. Dev. 26:619-631.

Frutos, J., S. Andrés, E. Trevisi, J. Benavides, N. Santos, A. Santos, and F. J. Giráldez. 2018. Moderated milk replacer restriction of ewe lambs alters gut immunity parameters during the pre-weaning period and impairs liver function and animal performance during the replacement phase. Anim. Feed Sci. Technol. 243:80-89. https: //doi.org/10.1016/j.anifeedsci.2018.07.009.

Fu, L., Y. Xu, Y. Hou, X. Qi, L. Zhou, H. Liu, Y. Luan, L. Jing, Y. Miao, S. Zhao, H. Liu, and X. Li. 2017. Proteomic analysis indicates that mitochondrial energy metabolism in skeletal muscle tissue is negatively correlated with feed efficiency in pigs. Sci. Rep. 7:45291. https://doi.org/10.1038/srep45291.

Galligan, J. J., and D. R. Petersen. 2012. The human protein disulfide isomerase gene family. Hum. Genomics 6:6. https://doi.org/ 10.1186/1479-7364-6-6.

Galvani, D. B., C. C. Pires, C. H. Hübner, S. Carvalho, and T. P. Wommerd. 2014. Growth performance and carcass traits of earlyweaned lambs as affected by the nutritional regimen of lactating ewes. Small Rumin. Res. 120:1-5. https://doi.org/10.1016/j .smallrumres.2014.03.008.

Geraghty, A. A., K. L. Lindsay, G. Alberdi, F. M. McAuliffe, and E. R. Gibney. 2016. Nutrition during pregnancy impacts offspring's epigenetic status - Evidence from human and animal studies. Nutr. Metab. Insights 8(Suppl. 1):41-47. https://doi.org/10.4137/NMI .S29527.

Gimenez, M. S., L. B. Oliveros, and N. N. Gomez. 2011. Nutritional deficiencies and phospholipid metabolism. Int. J. Mol. Sci. 12:2408-2433. https://doi.org/10.3390/ijms12042408.

Giráldez, F. J., P. Frutos, P. Lavín, and A. R. Mantecón. 1999. Body composition changes and energy retention in milk-fed lambs undergoing energy restriction. Small Rumin. Res. 31:127-133. https: //doi.org/10.1016/S0921-4488(98)00129-1.

Girard, J. 1986. Gluconeogenesis in late fetal and early neonatal life. Biol. Neonate 50:237-258. https://doi.org/10.1159/000242605.

Girard, J. 1990. Metabolic adaptations to change of nutrition at birth. Biol. Neonate 58(Suppl. 1):3-15. https://doi.org/10.1159/ 000243294

González-Barranco, J., and J. M. Ríos-Torres. 2004. Early malnutrition and metabolic abnormalities later in life. Nutr. Rev. 62:S134S139.

Goodman, M. N., P. R. Larsen, M. M. Kaplan, T. T. Aoki, V. R. Young, and N. B. Ruderman. 1980. Starvation in the rat. II. Effect of age and obesity on protein sparing and fuel metabolism. Am. J. Physiol. 239:E277-E286. https://doi.org/10.1152/ajpendo.1980 239.4.E277.

Greenwood, P. L., A. S. Hunt, and W. Bell. 2004. Effects of birth weight and postnatal nutrition on neonatal sheep: IV. Organ growth. J. Anim. Sci. 82:422-428. https://doi.org/10.2527/2004 $.822422 \mathrm{x}$.
Grubbs, J. K., A. N. Fritchen, E. Huff-Lonergan, N. K. Gabler, and S. M. Lonergan. 2013. Selection for residual feed intake alters the mitochondria protein profile in pigs. J. Proteomics 80:334-345. https://doi.org/10.1016/j.jprot.2013.01.017.

Idkowiak, J., A. E. Taylor, S. Subtil, D. M. O'Neil, R. Vijzelaar, R. P. Dias, R. Amin, T. G. Barrett, C. H. L. Shackleton, J. M. W. Kirk, C. Moss, and W. Arlt. 2016. Steroid sulfatase deficiency and androgen activation before and after puberty. J. Clin. Endocrinol. Metab. 101:2545-2553. https://doi.org/10.1210/jc.2015-4101.

James, W. P. T. 1972. Protein synthesis and breakdown and amino acid catabolism in protein-calorie malnutrition. Proc. Nutr. Soc. $31: 225-231$.

Jin, Z. G., A. O. Lungu, L. Xie, M. Wang, C. Wong, and B. C. Berk. 2004. Cyclophilin A is a proinflammatory cytokine that activates endothelial cells. Arterioscler. Thromb. Vasc. Biol. 24:1186-1191. https://doi.org/10.1161/01.ATV.0000130664.51010.28.

Jin, Z. G., M. G. Melaragno, D. F. Liao, C. Yan, J. Haendeler, Y. A. Suh, J. D. Lambeth, and B. C. Berk. 2000. Cyclophilin A is a secreted growth factor induced by oxidative stress. Circ. Res. 87:789-796. https://doi.org/10.1161/01.RES.87.9.789.

Kang, W., M. S. Lee, and M. Baik. 2011. Dietary protein restriction alters lipid metabolism and insulin sensitivity in rats. Asian-Aust. J. Anim. Sci. 24:1274-1281. https://doi.org/10.5713/ajas.2011 .10430.

Keogh, K., D. A. Kenny, P. Cormican, A. K. Kelly, and S. M. Waters. 2016. Effect of dietary restriction and subsequent re-alimentation on the transcriptional profile of hepatic tissue in cattle. BMC Genomics 17:244. https://doi.org/10.1186/s12864-016-2578-5.

Khanal, P., and M. O. Nielsen. 2017. Impacts of prenatal nutrition on animal production and performance: a focus on growth and metabolic and endocrine function in sheep. J. Anim. Sci. Biotechnol. 8:75. https://doi.org/10.1186/s40104-017-0205-1.

Lan, X., E. C. Cretney, J. Kropp, K. Khateeb, M. A. Berg, F. Peñagaricano, R. Magness, A. E. Radunz, and H. Khatib. 2013. Maternal diet during pregnancy induces gene expression and DNA methylation changes in fetal tissues in sheep. Front. Genet. 4:49. https://doi.org/10.3389/fgene.2013.00049.

Lee, E., and D. H. Lee. 2017. Emerging roles of protein disulfide isomerase in cancer. BMB Rep. 50:401-410. https://doi.org/10.5483/ BMBRep.2017.50.8.107.

Lillycrop, K. A., J. L. Slater-Jefferies, M. A. Hanson, K. M. Godfrey, A. A. Jackson, and G. C. Burdge. 2007. Induction of altered epigenetic regulation of the hepatic glucocorticoid receptor in the offspring of rats fed a protein-restricted diet during pregnancy suggests that reduced DNA methyltransferase- 1 expression is involved in impaired DNA methylation and changes in histone modifications. Br. J. Nutr. 97:1064-1073. https://doi.org/10.1017/ S000711450769196X

Love, M. I., W. Huber, and S. Anders. 2014. Moderated estimation of fold change and dispersion for RNA-seq data with DESeq2. Genome Biol. 15:550. https://doi.org/10.1186/s13059-014-0550-8.

Manso, T., A. R. Mantecón, T. Castro, and G. R. Iason. 1998. Effect of intake level during milk-feeding period and protein content in the postweaning diet on performance and body composition in growing lambs. Anim. Sci. 67:513-521. https://doi.org/10.1017/ S135772980003294X.

Morton, N. M., J. Beltram, R. N. Carter, Z. Michailidou, G. Gorjanc, C. Mc Fadden, M. E. Barrios-Llerena, S. Rodriguez-Cuenca, M. T. G. Gibbins, R. E. Aird, J. M. Moreno-Navarrete, S. C. Munger, K. L. Svenson, A. Gastaldello, L. Ramage, G. Naredo, M. Zeyda, Z. V. Wang, A. F. Howie, A. Saari, P. Sipilä, T. M. Stulnig, V. Gudnason, C. J. Kenyon, J. R. Seckl, B. R. Walker, S. P. Webster, D. R. Dunbar, G. A. Churchill, A. Vidal-Puig, J. M. Fernández-Real, V. Emilsson, and S. Horvat. 2016. Genetic identification of thiosulfate sulfurtransferase as an adipocyte-expressed antidiabetic target in mice selected for leanness. Nat. Med. 22:771-779. https://doi .org $/ 10.1038 / \mathrm{nm} .4115$

Nafikov, R. A., and D. C. Beitz. 2007. Carbohydrate and lipid metabolism in farm animals. J. Nutr. 137:702-705. https://doi.org/ 10.1093/jn/137.3.702. 
Nigro, P., G. Pompilio, and M. C. Capogrossi. 2013. Cyclophilin A: A key player for human disease. Cell Death Dis. 4:e888. https://doi .org/10.1038/cddis.2013.410.

NRC. 1985. Nutrient Requirements of Sheep. 6th ed. Natl. Acad. Press, Washington DC

R Core Team. 2016. R: A language and environmental for statistical computing. R Foundation for Statistical Computing, Vienna, Austria. https://www.R-project.org/.

Reed, M. J., A. Purohit, L. W. Woo, S. P. Newman, and B. V. Potter 2005. Steroid sulfatase: Molecular biology, regulation, and inhibition. Endocr. Rev. 26:171-202. https://doi.org/10.1210/er.2004 $-0003$

Robinson, J. J., C. J. Ashworth, J. A. Rooke, L. M. Mitchell, and T. G. McEvoy. 2005. Nutrition and fertility in ruminant livestock. Anim. Feed Sci. Technol. 126:259-276. https://doi.org/10.1016/j anifeedsci.2005.08.006

Robinson, M. D., D. J. McCarthy, and G. K. Smyth. 2010. edgeR: A Bioconductor package for differential expression analysis of digital gene expression data. Bioinformatics 26:139-140. https://doi.org/ 10.1093/bioinformatics/btp616.

Robinson, J. J., J. A. Rooke, and T. G. McEvoy. 2002. Nutrition for conception and pregnancy. Pages 189-211 in Sheep Nutrition. M. Freer and H. Dove, ed. CABI Publishing, Wallingford, UK.

Rodríguez, A. B., R. Landa, R. Bodas, N. Prieto, A. R. Mantecon, and F. J. Giraldez. 2008. Carcass and meat quality of Assaf milk fed lambs: Effect of rearing system and sex. Meat Sci. 80:225-230. https://doi.org/10.1016/j.meatsci.2007.11.023.

Roseboom, T. J., R. C. Painter, A. F. M. Van Abeelen, M. V. E. Veenendaal, and S. R. De Rooij. 2011. Hungry in the womb: What are the consequences? Lessons from the Dutch famine. Maturitas 70:141-145. https://doi.org/10.1016/j.maturitas.2011.06.017.

Ruchat, S.-M., L. Bouchard, and M.-F. Hivert. 2014. Early infant nutrition and metabolic programming: What are the potential molecular mechanisms? Curr. Nutr. Rep. 3:281-288. https://doi.org/ 10.1007/s13668-014-0088-0.

Salway, J. G. 2004. Metabolism at a Glance. 3rd ed. Blackwell Publishing Ltd., Malden, MA.

Santos, A., F. J. Giráldez, J. Mateo, J. Frutos, and S. Andrés. 2018a. Programming Merino lambs by early feed restriction reduces growth rates and increases fat accretion during the fattening period with no effect on meat quality traits. Meat Sci. 135:20-26. https://doi.org/10.1016/j.meatsci.2017.08.007.

Santos, A., F. J. Giráldez, E. Trevisi, L. Lucini, J. Frutos, and S. Andrés. 2018b. Liver transcriptomic and plasma metabolic profiles of fattening lambs are modified by feed restriction during the suckling period. J. Anim. Sci. 96:1495-1507. https://doi.org/10 $.1093 /$ jas/sky029.

Santos, A., F. J. Giráldez, C. Valdés, E. Trevisi, L. Lucini, J. Frutos, and S. Andrés. 2018c. Milk replacer restriction during the early life impairs the live body weight and progesterone patterns of ewe lambs during the replacement period. J. Dairy Sci. 101:8021-8031. https://doi.org/10.3168/jds.2018-14648.

Santos, A., C. Valdés, F. J. Giráldez, S. López, J. France, J. Frutos, M. Fernández, and S. Andrés. 2018d. Feed efficiency and the liver proteome of fattening lambs are modified by feed restriction during the suckling period. Animal 12:1838-1846. https://doi.org/10 $.1017 /$ S1751731118000046.

Sinclair, K. D., C. Allegrucci, R. Singh, D. S. Gardner, S. Sebastian, J. Bispham, A. Thurston, J. F. Huntley, W. D. Rees, C. A. Maloney, R. G. Lea, J. Craigon, T. G. McEvoy, and L. E. Young. 2007. DNA methylation, insulin resistance, and blood pressure in offspring determined by maternal periconceptional B vitamin and methionine status. Proc. Natl. Acad. Sci. USA 104:19351-19356. https://doi .org/10.1073/pnas.0707258104

Soberon, F., E. Raffrenato, R. W. Everett, and M. E. Van Amburgh. 2012. Preweaning milk replacer intake and effects on long-term productivity of dairy calves. J. Dairy Sci. 95:783-793. https://doi .org/10.3168/jds.2011-4391.

Soberon, F., and M. E. Van Amburgh. 2013. Lactation biology symposium: The effect of nutrient intake from milk or milk replacer of preweaned dairy calves on lactation milk yield as adults: A meta-analysis of current data. J. Anim. Sci. 91:706-712. https:// doi.org/10.2527/jas.2012-5834.

Sohal, R. S., H.-H. Ku, S. Agarwal, M. J. Forster, and H. Lal. 1994. Oxidative damage, mitochondrial oxidant generation and antioxidant defenses during aging and in response to food restriction in the mouse. Mech. Ageing Dev. 74:121-133. https://doi.org/10 .1016/0047-6374(94)90104-X.

Tizioto, P. C., L. L. Coutinho, J. E. Decker, R. D. Schnabel, K. O. Rosa, P. S. N. Oliveira, M. M. Souza, G. B. Mourão, R. R. Tullio, A. S. Chaves, D. P. D. Lanna, A. Zerlotini-Neto, M. A. Mudadu, J. F. Taylor, and L. C. A. Regitano. 2015. Global liver gene expression differences in Nelore steers with divergent residual feed intake phenotypes. BMC Genomics 16:242. https://doi.org/10.1186/ s12864-015-1464-x.

van den Borne, J. J., G. E. Lobley, M. W. A. Verstegen, J. M. Muijlaert, S. J. J. Alferink, and W. J. J. Gerrits. 2007. Body fat deposition does not originate from carbohydrates in milk-fed calves. J. Nutr. 137:2234-2241. https://doi.org/10.1093/jn/137.10.2234.

van Zutphen, T., J. Ciapaite, V. W. Bloks, C. Ackereley, A. Gerding, A. Jurdzinski, R. A. de Moraes, L. Zhang, J. C. Wolters, R. Bischoff, R. J. Wanders, S. M. Houten, D. Bronte-Tinkew, T. Shatseva, G. F. Lewis, A. K. Groen, D. J. Reijngoud, B. M. Bakker, J. W. Jonker, P. K. Kim, and R. H. Bandsma. 2016. Malnutritionassociated liver steatosis and ATP depletion is caused by peroxisomal and mitochondrial dysfunction. J. Hepatol. 65:1198-1208. https://doi.org/10.1016/j.jhep.2016.05.046.

Velez, J. C., and S. S. Donkin. 2005. Feed restriction induces pyruvate carboxylase but not phosphoenolpyruvate carboxykinase in dairy cows. J. Dairy Sci. 88:2938-2948. https://doi.org/10.3168/ jds.S0022-0302(05)72974-X.

Vincent, A., I. Louveau, F. Gondret, C. Tréfeu, H. Gilbert, and L. Lefaucheur. 2015. Divergent selection for residual feed intake affects the transcriptomic and proteomic profiles of pig skeletal muscle. J. Anim. Sci. 93:2745-2758. https://doi.org/10.2527/jas.2015-8928.

Wood, T. 1985. The Pentose Phosphate Pathway. Academic Press, Orlando, FL.

Xu, J., S. R. Kulkarni, L. Li, and A. L. Slitt. 2012. UDP-glucuronosyltransferase expression in mouse liver is increased in obesity- and fasting-induced steatosis. Drug Metab. Dispos. 40:259-266. https: //doi.org/10.1124/dmd.111.039925.

Yu, C., J. K. Ritter, R. J. Krieg, B. Rege, H. T. Karnes, and M. A. Sarkar. 2004. Effect of food restriction on UDP-glucuronosyltransferase (UGT) enzymes in liver. Clin. Pharmacol. Ther. 75:85. https://doi.org/10.1016/j.clpt.2003.11.326.

Zhang, L., W. Voskuijl, M. Mouzaki, A. K. Groen, J. Alexander, C. Bourdon, A. Wang, C. J. Versloot, V. Di Giovanni, R. J. Wanders, and R. Bandsma. 2016. Impaired bile acid homeostasis in children with severe acute malnutrition. PLoS One 11:e0155143. https:// doi.org/10.1371/journal.pone.0155143. 